\title{
INFERENSI DATA UJI HIDUP TERSENSOR TIPE II BERDISTRIBUSI RAYLEIGH
}

\author{
Oleh : \\ Tatik Widiharih ${ }^{1}$ Wiwin Mardjiyati ${ }^{2}$ \\ ${ }^{1}$ Staf Program Studi Statistika FMIPA UNDIP \\ ${ }^{2}$ Alumni Program Studi Statistika FMIPA UNDIP
}

\begin{abstract}
Analysis of life time is one of statistical analysis which many utilized in industry and healt. Life time data having a form complete or censor data, that is a nonnegative random variable. Determination of point estimation is utilized MLE (maximum likelihood estimator), goodness of fit distribution is utilized Andersson Darling methods. Point estimation of life time test report on mean time to failure (MMTF), hazard fuction $h(t)$, survival function $\mathrm{S}(\mathrm{t})$. Interval estimation is utilized pivotal quantity methods.
\end{abstract}

Key words : censor data, MLE, mean time to failure, hazard function, survival function.

\section{PENDAHULUAN}

Analisis data uji hidup merupakan salah satu teknik statistika yang berguna untuk melakukan pengujian tentang tahan hidup atau keandalan suatu komponen ataupun pengukuran lamanya tahan hidup seorang pasien dalam pengobatan suatu penyakit ${ }^{[3]}{ }^{[4]}$. Keandalan dapat diartikan sebagai probabilitas tidak terjadinya kegagalan atau kerusakansuatu alat untuk melakukan fungsinya secara wajar selama periode operasi yang ditentukan ${ }^{[2]}$. Dalam melakukan analisis data uji hidup dibutuhkan data tahan hidup yang meliputi waktu tahan hidup dan status waktu tahan hidup dari object yang diteliti. Data waktu hidup yang diperoleh dapat berupa data lengkap (semua object dicatat daya tahan hidupnya sampai semua mati) atau data tersensor (diamati sampai waktu yang ditentukan (tersensor tipe I) atau diamati sampai sebagian object ( $\mathrm{r}$ buah) dari semua object yang diteliti (n) telah mati sehingga masih ada sebagian object yang masih tetap hidup (n-r buah) biasa dikenal dengan tersensor tipe II)

Ada tiga macam tipe penyensoran data yaitu :

1. Sensor tipe I. Semua object yang diteliti (n) masuk pengujian dalam waktu yang bersamaan, dan pengujian dihentikan setelah batas waktu $t_{0}$ yang ditentukan ${ }^{[2][3][4]}$ ${ }^{[5]}$. Kelemahan dari sensor tipe $\mathrm{I}$ ini bisa terjadi sampai batas waktu $\mathrm{t}_{0}$ yang ditentukan semua object masih hidup sehingga tidak diperoleh data tahan hidup dari object yang diuji.

2. Sensor tipe II. Semua object yang diteliti (n) masuk pengujian dalam waktu yang bersamaan, dan pengujian dihentikan setelah mendapatkan $r$ object diantaranya mati, dengan $1 \leq \mathbf{r} \leq \mathbf{n}$. [2] [3] [4] [5]. Kelemahan dari sensor tipe II ini waktu yang diperlukan untuk memperoleh $r$ object yang mati bisa jadi sangat panjang, tetapi pasti diperoleh data tahan hidup dari $r$ object tersebut.

3. Sensor tipe III. Object masuk dalam pengujian pada waktu yang tidak bersamaan selama periode waktu yang telah ditentukan. Beberapa object yang mati / gagal sebelum pengamatan berakhir mempunyai data tahan hidup, sebagian lain masih tetap hidup sampai waktu pengujian berakhir, sebagian lagi ada yang masih hidup tetapi keluar dari pengujian (pada kasus object berupa manusia / pasien yang menjalani terapi tertentu) ${ }^{[4]}$.

Distribusi Rayleigh merupakan bentuk khusus dari distribusi Weibull, sehingga inferensi yang dibuat ada analogi dengan distribusi Weibull. Berdasarkan hal tersebut 
diatas tujuan dari tulisan ini adalah membuat inferensi data tahan hidup tersensor tipe II untuk distribusi Rayleigh. Uji kecocokan distribusi menguunakan metode Anderson Darling, estimasi titik menggunakan metode likelihood maksimum dan estimasi interval menggunakan metode besaran pivot. Untuk memperjelas pembahaaasan diberikan contoh kasus object yang diteliti tahan hidup kapasitor keramik.

\section{DESKRIPSI TEORITIS}

\subsection{Konsep Dasar Uji Tahan Hidup}

Waktu tahan hidup T merupakan variabel random kontinue nonnegatif. Distribusi peluang dari $\mathrm{T}$ dapat dinyatakan dalam tiga cara :

1. Fungsi ketahanan (survival function) $\mathrm{S}(\mathrm{t})$

2. Fungsi kepadatan peluang $\mathrm{f}(\mathrm{t})$

3. Fungsi kegagalan (hazard function) $h(t)$

Ketiga fungsi ini secara matematika adalah saling ekuivalen, artinya jika salah satu dari ketiga fungsi ini diketahui, maka fungsi-fungsi yang lainnya dapat ditentukan. Definisi dari fungsi ketahanan dan fungsi kegagalan sebagai berikut :

- Fungsi ketahanan

$$
\mathrm{S}(\mathrm{t})=\mathrm{P}(\mathrm{T}>\mathrm{t})=1-\mathrm{P}(\mathrm{T} \leq \mathrm{t})=1-\mathrm{F}(\mathrm{t})
$$

- Fungsi kegagalan

$$
h(t)=\frac{f(t)}{1-F(t)}=\frac{f(t)}{S(t)}
$$

\subsection{Distribusi Rayleigh}

Fungsi kepadatan peluang untuk data tahan hidup berdistribusi Rayleigh adalah :

$$
f(t \mid \theta)=\frac{t}{\theta^{2}} \exp \left[-\frac{t^{2}}{2 \theta^{2}}\right] \quad t>0 \quad \theta>0
$$

Estimator Maksimum Likelihood dari $\theta$ :

$$
\begin{array}{r}
\mathrm{L}(\theta \mid \underset{\sim}{\mathrm{T}})=\theta^{-2 \mathrm{n}} \prod_{\mathrm{i}=1}^{\mathrm{n}} \mathrm{t}_{\mathrm{i}} \cdot \exp \left[-\frac{1}{2 \theta^{2}} \sum_{\mathrm{i}=1}^{\mathrm{n}} \mathrm{t}_{\mathrm{i}}^{2}\right] \\
\ln [\mathrm{L}(\theta \mid \underset{\sim}{\mathrm{T}})]=-2 \mathrm{n} \ln \theta+\sum_{\mathrm{i}=1}^{\mathrm{n}} \ln \left(\mathrm{t}_{\mathrm{i}}\right)-\frac{1}{2 \theta^{2}} \sum_{\mathrm{i}=1}^{\mathrm{n}} \mathrm{t}_{\mathrm{i}}^{2} \\
\frac{\partial \ln [\mathrm{L}(\theta \mid \underset{\sim}{\mathrm{T}})]}{\partial \theta}=0 \text { maka } \quad-\frac{2 \mathrm{n}}{\hat{\theta}}+\frac{\sum_{\mathrm{i}=1}^{\mathrm{n}} \mathrm{t}_{\mathrm{i}}^{2}}{\hat{\theta^{3}}}=0 \\
\hat{\theta}=\sqrt{\frac{1}{2 \mathrm{n}} \sum_{\mathrm{i}=1}^{\mathrm{n}} \mathrm{t}_{\mathrm{i}}^{2}}
\end{array}
$$




\section{INFERENSI UJI TAHAN HIDUP UNTUK DISTRIBUSI RAYLEIGH}

\subsection{Konsep Uji Tahan Hidup pada Distribusi Rayleigh}

a. Fungsi kepadatan peluang dari distribusi Rayleigh seperti pada persamaan (3) :

$$
\mathrm{f}(\mathrm{t} \mid \theta)=\frac{\mathrm{t}}{\theta^{2}} \exp \left[-\frac{\mathrm{t}^{2}}{2 \theta^{2}}\right] \quad \mathrm{t}>0 \quad \theta>0
$$

b. Fungsi distribusi kumulatif dari distribusi Rayleigh :

$$
F(t)=\int_{0}^{t} \frac{x}{\theta^{2}} \cdot \exp \left[-\frac{x^{2}}{2 \theta^{2}}\right] d x=1-\exp \left[-\frac{t^{2}}{2 \theta^{2}}\right] .
$$

c. Fungsi ketahanan :

$$
\mathrm{S}(\mathrm{t})=1-\mathrm{F}(\mathrm{t})=\mathrm{S}(\mathrm{t})=1-\mathrm{F}(\mathrm{t})=\exp \left[-\frac{\mathrm{t}^{2}}{2 \theta^{2}}\right]
$$

d. Fungsi kegagalan :

$$
h(t)=\frac{f(t)}{S(t)}=\frac{t}{\theta^{2}}
$$

\subsection{Mean Time To Failure (MTTF) untuk Distribusi Rayleigh}

Salah satu komponen dari ketahanan adalah rata-rata waktu kegagalan atau Mean Time

To Failure (MTTF). Estimasi rata-rata waktu kegagalan ( MTTF) adalah :

$$
\hat{\mathrm{MTTF}}=\int_{0}^{\infty} \mathrm{t} . \mathrm{f}(\mathrm{t}) \mathrm{dt}
$$

Dari bentuk tersebut terlihat bahwa $\mathrm{MTTF}=\mathrm{E}(\mathrm{T})$, notasikan $\mathrm{MTTF}=\mu$

$$
\hat{\operatorname{MTTF}}=\int_{0}^{\infty} \mathrm{t} \cdot \frac{\mathrm{t}}{\theta^{2}} \exp \left[-\frac{\mathrm{t}^{2}}{2 \theta^{2}}\right] \mathrm{dt}=\sqrt{\frac{\theta^{2} \pi}{2}}
$$

\subsection{Data Tersensor Tipe II untuk Distribusi Rayleigh}

Misalkan $\mathrm{n}$ object merupakan sampel random dari populasi yang berdistribusi Rayleigh dengan fungsi kepadatan peluang seperti pada persamaan (3), akan diuji tahan hidupnya pada kondisi normal dengan sensor tipe II. Tahan hidup dari $\mathrm{r}$ object pertama yang gagal dicatat sebagai statistik berurut $\mathrm{t}_{(1)} \leq \mathrm{t}_{(2)} \leq \ldots . . \leq \mathrm{t}_{(\mathrm{r})}$, untuk pembahasan selanjutnya ditulis dengan : $\mathrm{t}_{1} \leq \mathrm{t}_{2} \leq \ldots . \leq \mathrm{t}_{\mathrm{r}}$. Dalam hal ini masih ada (n-r) object yang masih tetap hidup pada saat uji dihentikan. Fungsi kepadatan peluang bersama $t_{1} \leq t_{2} \leq \ldots . \leq$ $\mathrm{t}_{\mathrm{r}}$ adalah :

$$
\begin{aligned}
& \begin{aligned}
\mathrm{f}\left(\mathrm{t}_{1}, \mathrm{t}_{2}, \ldots, \mathrm{t}_{\mathrm{r}} ; \theta\right) & =\frac{\mathrm{n} !}{(\mathrm{n}-\mathrm{r}) !}\left[\prod_{\mathrm{i}=1}^{\mathrm{r}} \mathrm{f}(\mathrm{t})\right]\left[\mathrm{S}\left(\mathrm{t}_{\mathrm{r}}\right)\right]^{\mathrm{n}-\mathrm{r}} \\
& =\frac{\mathrm{n} !}{(\mathrm{n}-\mathrm{r}) !} \frac{1}{\theta^{2 r}} \prod_{\mathrm{i}=1}^{\mathrm{r}} \mathrm{t}_{\mathrm{i}} \cdot \exp \left[-\frac{\mathrm{T}^{2}}{2 \theta^{2}}\right]
\end{aligned} \\
& \text { dengan } \mathrm{T}^{2}=\sum_{\mathrm{i}=1}^{\mathrm{r}} \mathrm{t}_{\mathrm{i}}^{2}+(\mathrm{n}-\mathrm{r}) \mathrm{t}_{\mathrm{r}}^{2}
\end{aligned}
$$


MLE untuk $\theta$ :

$$
\begin{aligned}
& L(\theta, T)=\frac{n !}{(n-r) !} \frac{1}{\theta^{2 r}} \prod_{i=1}^{r} t_{i} \cdot \exp \left[-\frac{T^{2}}{2 \theta^{2}}\right] \\
& \ln (\mathrm{L}[\theta, \mathrm{T}])=\ln \frac{\mathrm{n} !}{(\mathrm{n}-\mathrm{r}) !}-2 \mathrm{r} \ln \theta+\sum_{\mathrm{i}=1}^{\mathrm{r}} \ln \left(\mathrm{t}_{\mathrm{i}}\right)-\frac{\mathrm{T}^{2}}{2 \theta^{2}} \\
& \frac{\partial \ln (\mathrm{L}[\theta, \mathrm{T}])}{\partial \theta}=0 \\
& -\frac{2 \mathrm{r}}{\hat{\theta}}+\frac{\mathrm{T}^{2}}{\hat{\theta}^{3}}=0 \text { maka } \hat{\theta}=\sqrt{\frac{\mathrm{T}^{2}}{2 \mathrm{r}}} \\
& \hat{\operatorname{MTTF}}=\sqrt{\frac{\hat{\theta^{2} \pi}}{2}}=\frac{1}{2} \sqrt{\frac{\mathrm{T}^{2} \pi}{\mathrm{r}}} \\
& \hat{\mu}=\hat{\theta} \sqrt{\frac{\pi}{2}}
\end{aligned}
$$

Lemma $1 .^{[3]}$

Misalkan $\mathrm{T}$ variabel random berdistribusi Rayleigh $(\theta)$, dengan : $\mathrm{t}_{1} \leq \mathrm{t}_{2} \leq \ldots . \leq \mathrm{t}_{\mathrm{r}}$ adalah sampel terurut berukuran $r$ dari populasi yang berukuran $\mathrm{n}$, maka :

1. Estimator untuk $\theta^{2}$ yaitu $\hat{\theta}^{2}=\frac{T^{2}}{2 r}$ dengan $T^{2}=\sum_{i=1}^{r} t_{i}^{2}+(n-r) t_{r}^{2}$ adalah estimator yang takbias untuk $\theta^{2}$.

2. $\frac{\mathrm{T}^{2}}{\theta^{2}} \sim \chi_{2 \mathrm{r}}^{2}$

Bukti :

1.a. Dibuat transformasi $y_{i}=\frac{t_{i}^{2}}{2}$, dengan transformasi ini $y_{i} \sim \operatorname{Exp}\left(\theta^{2}\right)$

b. Dicari fungís kepadatan peluang bersama dari $\mathrm{y}_{\mathrm{i}}$ berikut :

$$
f(\underset{\sim}{y} \mid \theta)=\frac{1}{\theta^{2 r}} \cdot \exp \left[-\frac{1}{\theta^{2}} \sum_{i=1}^{r} y_{i}\right]
$$

c. Bentuk transformasi $\mathrm{W}_{\mathrm{i}}=(\mathrm{n}-(\mathrm{i}-1))\left(\mathrm{y}_{\mathrm{i}}-\mathrm{y}_{\mathrm{i}-1}\right), \mathrm{i}=2,3, \ldots, \mathrm{r}$ dengan $\mathrm{y}_{0}=0$

Sehingga $\sum_{\mathrm{i}=1}^{\mathrm{r}} \mathrm{W}_{\mathrm{i}}=\frac{1}{2}\left[\sum_{\mathrm{i}=1}^{\mathrm{r}} \mathrm{t}_{\mathrm{i}}^{2}+(\mathrm{n}-\mathrm{r}) \mathrm{t}_{\mathrm{r}}^{2}\right]$ dan $\quad \mathrm{W}_{\mathrm{i}} ; \mathrm{i}=1,2, . ., \mathrm{r} \quad$ variable random independen berdistribusi Exponensial dengan parameter $\theta^{2}$. Dari langkah ini sifat takbias terbukti.

2. Berdasarkan langkah 1.c. fungsi pembangkit momen untuk $\sum_{i=1}^{r} \mathrm{~W}_{\mathrm{i}}$ hádala : 


$$
\begin{aligned}
& \mathrm{M}_{\sum_{i=1}^{r} \mathrm{w}_{\mathrm{i}}}(\mathrm{t})=\left(1-\theta^{2} \mathrm{t}\right)^{-\mathrm{r}} \\
& \mathrm{M}_{\sum_{\mathrm{i}=1}^{r} \mathrm{w}_{\mathrm{i}}}\left(\frac{2 \mathrm{t}}{\theta^{2}}\right)=(1-2 \mathrm{t})^{-2 \mathrm{r} / 2} \\
& \text { Sehingga } \frac{2 \sum_{\mathrm{i}=1}^{\mathrm{r}} \mathrm{W}_{\mathrm{i}}}{\theta^{2}}=\frac{\mathrm{T}^{2}}{\theta^{2}} \sim \chi_{2 \mathrm{r}}^{2}
\end{aligned}
$$

Estimasi interval untuk $\theta$.

Berdasarkan $\frac{T^{2}}{\theta^{2}} \sim \chi_{2 \mathrm{r}}^{2}$, interval (1- $\alpha$ ). $100 \%$ untuk $\theta$ adalah :

$$
\begin{gathered}
\mathrm{P}\left(\chi_{1-\alpha / 2 ; 2 \mathrm{r}}^{2}<\frac{\mathrm{T}^{2}}{\theta^{2}}<\chi_{\alpha / 2 ; 2 \mathrm{r}}^{2}\right)=1-\alpha \\
\sqrt{\frac{\mathrm{T}^{2}}{\chi_{\alpha / 2 ; 2 \mathrm{r}}^{2}}}<\theta<\sqrt{\frac{\mathrm{T}^{2}}{\chi_{1-\alpha / 2 ; 2 \mathrm{r}}^{2}}} \ldots \ldots \ldots \ldots . . . . .
\end{gathered}
$$

Berdasarkan persamaan (10) maka interval $(1-\alpha) .100 \%$ untuk MTTF $=\mu$ adalah :

$$
\begin{gathered}
\sqrt{\frac{\mathrm{T}^{2}}{\chi_{\alpha / 2 ; 2 \mathrm{r}}^{2}}}<\frac{\mu}{\sqrt{\frac{\pi}{2}}}<\sqrt{\frac{\mathrm{T}^{2}}{\chi_{1-\alpha / 2 ; 2 \mathrm{r}}^{2}}} \\
\sqrt{\frac{\mathrm{T}^{2} \pi}{2 \chi_{\alpha / 2 ; 2 \mathrm{r}}^{2}}}<\mu<\sqrt{\frac{\mathrm{T}^{2} \pi}{2 \chi_{1-\alpha / 2 ; 2 r}^{2}}}
\end{gathered}
$$

Estimasi fungsi ketahanan :

$$
\hat{\mathrm{S}(\mathrm{t})}=\exp \left[-\frac{\mathrm{t}^{2}}{2 \hat{\theta}^{2}}\right]=\exp \left[-\frac{\mathrm{rt}^{2}}{\sum_{\mathrm{i}=1}^{\mathrm{r}} \mathrm{t}_{\mathrm{i}}^{2}+(\mathrm{n}-\mathrm{r}) \mathrm{t}_{\mathrm{r}}^{2}}\right] \ldots \ldots \ldots \ldots \ldots \ldots
$$

Berdasarkan persamaan (10) diperoleh interval (1- $\alpha) .100 \%$ untuk $S(t)$ pada $t=t_{0}$ sebagai berikut :

$$
\exp \left[-\frac{\mathrm{t}_{0}^{2}}{2 \sqrt{\frac{\mathrm{T}^{2}}{\chi_{\alpha / 2 ; 2 \mathrm{r}}^{2}}}}\right]<\mathrm{S}\left(\mathrm{t}_{0}\right)<\exp \left[-\frac{\mathrm{t}_{0}^{2}}{2 \sqrt{\frac{\mathrm{T}^{2}}{\chi_{1-\alpha / 2 ; 2 \mathrm{r}}^{2}}}}\right]
$$

3.4. Uji Kecocokan Distribusi.

Uji kecocokan distribusi ini perlu dilakukan untuk mengetahui apakah data yang dipunyai mengikuti distribusi tertentu. Hal ini karena bentuk distribusi menentukan 
inferensi yang akan dilakukan. Dalam tulisan ini digunakan metode Anderson Darling ${ }^{[3]}$ sebagai berikut :

$$
\mathrm{H}_{0}: \mathrm{F}(\mathrm{t})=\mathrm{F}_{0}(\mathrm{t}) \quad \text { vs } \quad \mathrm{H}_{1}: \mathrm{F}(\mathrm{t}) \neq \mathrm{F}_{0}(\mathrm{t})
$$

Statistik Anderson Darling untuk data tersensor tipe II adalah :

$$
\begin{aligned}
\mathrm{A}_{\mathrm{n}, \mathrm{r}}^{2}= & -\sum_{\mathrm{i}=1}^{\mathrm{r}}\left[\frac{2 \mathrm{i}-1}{\mathrm{n}} \log \mathrm{F}_{0}\left(\mathrm{t}_{(\mathrm{i})}\right)-\frac{2 \mathrm{n}-2 \mathrm{i}+1}{\mathrm{n}} \log \left(1-\mathrm{F}_{0}\left(\mathrm{t}_{(\mathrm{i})}\right)\right)\right]+ \\
& \frac{\mathrm{r}^{2}}{\mathrm{n}} \log \mathrm{F}_{0}\left(\mathrm{t}_{(\mathrm{r})}\right)-\frac{(\mathrm{n}-\mathrm{r})^{2}}{\mathrm{n}} \log \left(1-\mathrm{F}_{0}\left(\mathrm{t}_{(\mathrm{r})}\right)\right)-\mathrm{nF}_{0}\left(\mathrm{t}_{(\mathrm{r})}\right)
\end{aligned}
$$

Dengan $\mathrm{n}$ banyaknya object yang diuji dan $\mathrm{r}$ banyaknya object yang gagal. Tolak $\mathrm{H}_{0}$ jika :

$$
\mathrm{A}_{\mathrm{n}, \mathrm{r}}^{2}>\mathrm{D}_{\mathrm{n}, \mathrm{p}}^{\alpha} \text { dengan } \mathrm{p}=\frac{\mathrm{r}}{\mathrm{n}} \text { dan } \mathrm{D}_{\mathrm{n}, \mathrm{p}}^{\alpha} \text { tabel pada lampiran } 1 .
$$

\section{Dartar Pustaka :}

1. Bain, L.J and Engelhard, M : Introduction to Probability and Mathematical Statistics, second edition. Duxbury Press, California (1991)

2. Elsayed, E.A : Reliability Enginering. Addison Wesley Longman, Inc, New York (1996)

3. Lawless, J.E : Statistical Model and Methods for Life Time Data. John Wiley \& Sons Inc, Canada (1982).

4. Lee, T.E : Statistical Methods for Survival Data Analysis. John Wiley \& Sons Inc, Canada (1992).

5. Wuryandari, T dan Widiharih, $\mathrm{T}$ : Inferensi Data Uji Hidup Tersensor Tipe II pada Distribusi Weibull. Jurnal matematika dan Komputer, volume 2 no.3 hal 165-174, Jurusan Matematika FMIPA UNDIP (1999). 